45 per cent relative humidity), they will absorb one pound of water when taken outside and allowed to re-condition at $40^{\circ} \mathrm{F} .\left(4 \cdot 4^{\circ}\right.$ C.) and 95 per cent relative humidity. In so doing they will liberate 1,200 B.Th.U. of heat. This amount of heat will provide excellent protection against the chill of a sudden temperature change provided that it is liberated at a suitable rate, and Dr. Cassie proceeded to show that the conditions within a fabric are such as to ensure that this heat is liberated at the optimum rate for protection against a sudden change of temperature.

The fibres are always in equilibrium with the air immediately surrounding them because absorption and desorption of water take place very rapidly; but the amount of water vapour absorbed from the air is so small compared with the water content of the fibres that their regain is virtually unchanged. The temperature of the air issuing from a mass of wool is therefore determined by the condition imposed by the fibres, namely, that the relative humidity must remain unchanged. The heat obtained. by condensing enough water vapour from any given volume of air to maintain a constant relative humidity when its temperature is decreased by 1 deg. C. is roughly equal to the heat required to raise the temperature of the air in the given volume by 1 deg. C. Thus, if the temperature of the air coming into contact with the textile is reduced by $10 \mathrm{deg}$. C. without change in the water vapour pressure, the air after passing through the textile will only be reduced by 5 deg. C., enough water having been condensed from the air by the textile to raise its temperature by $5 \mathrm{deg}$. C. This thermostatic effect of textiles is maintained over considerable periods because, fortunately, the diffusion constants for heat and for water vapour are almost the same, being $0.21 \mathrm{~cm} .{ }^{2} / \mathrm{sec}$. and $0.25 \mathrm{~cm} .{ }^{2} / \mathrm{sec}$, respectively. Thus the temperature and water vapour gradients are correctly maintained for securing the maximum effect in reducing the chill produced by a decrease in temperature.

The results of experiments designed to test the accuracy of these theoretical conclusions were then described by Dr. Cassie, who showed that excellent quantitative agreement has been obtained between the theoretical and actual results. The effect was studied of increasing the temperature of the air, passing through a mass of fibre, from $20^{\circ}$ to $35^{\circ} \mathrm{C}$. without change of vapour pressure, and it was found that the change in temperature of the emerging air was halted at $26^{\circ} \mathrm{C}$. The subsequent rate of increase in temperature was small, being least of all for wool and increasing in the order, wool, flax, silk and cotton. This corresponds to the order of the regains of the fibre, and, as predicted by the theory, the protection afforded by the fibres increases with the slope of the regain - relative humidity curves.

Finally, Dr. Cassie pointed out that a similar large thermostatic effect can result from textile furnishings. The increase in regain of a carpet when a room is left unheated results in the liberation of as much heat as would be given off by a $1-\mathrm{kW}$. electric fire burning for $1 \frac{1}{2}-2 \frac{1}{2} \mathrm{hr}$., the heat being liberated over a period of several days.

In the discussion which followed these two papers, Dr. R. W. Powell described experiments made at H.M. Norfolk Flax Establishment on the moisture relations of the growing flax plant, and pointed out that the normal date of pulling flax corresponds to the time at which the whole plant has a uniform moisture content. He mentioned experiments made on the heating up of stacks of flax straw and also described how the humidification of dry flax straw before scutching increases the yield of flax fibre.

Miss M. V. Griffiths asked whether the airing of domestic linen is really necessary, as a large amount of electricity is being consumed in modern houses for this purpose. Should the air movement be increased during drying in an airing cupboard or could a more efficient drying cupboard be designed? In reply, Mr. Matthew said that he regarded airing as a safety measure; linens stored in a folded condition in drawers would have little access to free air and so would not dry if they were put away damp. The rate of drying increases with increasing air velocity and temperature; usually the most economical method is to use some heat and a definite but not necessarily very large air velocity, on well exposed material. Dr. Cassie said that it is necessary for underwear to be dried to a low regain ; measurements have shown that, in the absence of perspiration, the air between the skin and underclothing has a relative humidity of only about 20 per cent, and underclothing should therefore be conditioned to this relative humidity by airing. J. L. SPENCER-SMITH

\section{AFFORESTATION OF MOORLAND}

$A \mathrm{~T}$ the meeting of the British Association in Belfast, Section $\mathrm{K}^{*}$ (Forestry) devoted a session during the morning of September 8 to the consideration of sylvicultural problems resulting from recent large-scale planting on moorland soils. The need for a considerable extension of the forest area in Britain - a need admitted by men of all shades of opinion-.has led to the formation of large plantations on heathland and moorland mainly in the upland regions. The current annual planting programme, in State forests alone, of approximately sixty thousand acres requires the use of large areas of these types of land, and work has been going on actively since 1919 in such diverse conditions as those afforded, for example, by the Yorkshire moors, the peat-covered Border country, the upland heaths of north-east Scotland, of Wales and of south-west England, and the blanket bog of the north-west of England. In forming their plantations, foresters had little to guide them at first except the existence of one or two relatively small plantations, the history of which had been recorded. They have had to hammer out their own technique. The need for carefully conducted experimental work was early recognized, and the large number of experiments carried out in the west and in the north, covering a wide range of subjects, such as choice of species, methods of planting, ploughing, drainage and the use of fertilizers, has had a marked influence on the course of events.

J. M. B. Brown (Forest Research Station, Alice Holt), in a paper on "The Role of Indicator Plants in Moorland Afforestation", discussed the use of the natural flora of moorlands and heathlands as a guide in the selection of tree species for planting. The vegetation on the ground before planting has been extensively used during the past thirty years for determining what land is plantable and what is unplantable and for allocating tree species to the various sites. Interpreted with discretion, the natural flora may give useful information by indicating which species of tree appears to be suitable to the local 


\section{No. 4331 November 1, 1952}

onditions of soil and climate. In Great Britain, however, there is, even now, comparatively little evidence which helps to correlate the performance of trees throughout their life-time with the vegetation at the time of planting. The difficulties of the problem have been greatly inereased by the use of exotic conifers in moorland afforestation, for many of these trees have been widely used only during the past thirty years and some of them have scarcely been studied ecologically in their native habitats. The natural vegetation may also suggest the kind of difficulty to be expected in establishing trees on the site and the degree to which individual species will be susceptible to these difficulties. Here, there is much more experience which may safely be relied on, but the occasional inconsistencies which occur emphasize the need for caution in making broad generalizations. The character of the vegetation has been little used as a guide in deciding which types of moorland should be ploughed before planting, as the use of the plough has now become general. Nevertheless, an examination of the plant community present before ploughing will usually tell what is likely to succeed it after ploughing and how rapidly the changes will take place. This is important in assessing the competition which the young trees will have to face.

Trees which will ultimately give a good account of themselves on moorland may be very difficult and costly to establish; on the other hand, trees which are comparatively easy to establish may not prove adapted to conditions in later life. Both the longterm and the short-term aspects must be kept in view.

The classification of moorlands for afforestation should not be based wholly on the occurrence of $a$ few familiar and easily recognized dominant plants, which, because of their wide tolerance, may be apt to mislead. Regard must also be paid to the lessconspicuous associates, to notable absentees, to the height, luxuriance and health of the dominants, and to evidence of disturbance by grazing, burning and peat-cutting.

"Recent Work on the Problems of Moorland Afforestation" was discussed in a paper by J. W. I. Zehetmayr (Research Branch, Forestry Commission, Edinburgh), who stated that one of the main functions of sylvicultural research at the present time is to increase the area of 'plantable' land by making it possible to afforest land which is at present classed as 'unplantable'. This may also have the effect of improving production on ground already regarded as suitable for planting. Experimental plantations, made at various times since 1921, have, in many cases, served as pilot schemes which have since been followed by extensive plantations on ground that was originally regarded as of doubtful value for forestry. In other instances, experimental plantations, though tolerably successful, have not yet inspired sufficient confidence for more widespread application of their results; examples of these may be found on deep basin peats and on thinner slope peats in the northwest of Scotland.

In the afforestation of peat, the first consideration is drainage, and drains are now invariably used to provide turves in which the young trees are set in planting. It was shown in early work that the more turf a plant has round about it, the better it grows. The provision of more turf for each plant led to more surface-draining by ditches, but so long as all the work had to be done by hand the economic limit was soon reached. Nowadays the draining plough is used to provide a continuous strip of upturned turf on which planting can be done. This has given satisfactory growth; but the system of equally sized drains, one alongside each row of plants, raises difficulties in subsequent maintenance, while the drains do not run sufficient water to clean themselves. One solution is to use two ploughs, a large plough such as the 'Cuthbertson' to make the main drains, and a lighter, shallower plough, like the 'Begg' or the 'Haddington', to provide material for turf-planting. The use of mechanical methods has decreased the quality of the work, as it is less easy with machines to site the main drains correctly. The Norwegian method of making very large deep drains at wider intervals and of using explosives in their formation is now receiving attention in Great Britain. It may have uses on land where ploughing is impossible.

Draining is not a problem on the heaths, most of which lie in the drier, eastern half of Britain; but ploughing, which is now the standard practice on these sites, leads to the disappearance of surface water which often lies long, while the rupture of the pan allows water to percolate through the soil so that no drains for removing water from the area are nécessary. Ploughing has greatly improved the early growth of trees on heathland. The current method of ploughing is to cut a deep furrow every five feet with a heavy plough which breaks the pan and throws up a ridge of spoil. Other methods, such as complete ploughing to a less depth, and the use of a 'tine' plough, are being tried experimentally. An important advance is the introduction of the hydraulic-lift tractor, which greatly increases ease of manouvring and allows the plough to be lifted over boulders and rock outerops. On difficult sites it is usual to apply ground mineral phosphate or highgrade basic slag at the rate of $1 \frac{1}{2}-2 \mathrm{oz}$. to each plant. Recent work by E. M. Crowther has shown that nitrogenous fertilizers improve the growth of newly planted trees on heathland.

On difficult or on marginal sites it is important to use the best 'strain' or 'race' of the tree which is selected for planting. One aspect of this was dealt with by J. A. B. Macdonald (Forestry Commission, Dumfries) in his paper on "The Place of Pinus contorta in British Sylviculture". This pine, a native of western North America, has come into prominence lately as a result of its success as a planted tree on poor peat and heathland sites. It has a wide range in North America, along the Pacific coast from Alaska to California, and inland into the Rocky Mountains. With such a range of altitude and latitude it naturally varies, the two extreme forms being recognized as the beach or shore pine, $P$. contorta Dougl. ex Loud, and the inland lodgepole pine, $P$. contorta var. latifolia Engelm. The former is a strong-growing coarsely branched tree, with dark green foliage, which throws a comparatively heavy shade; the latter has normally a straighter stem, finer and more open branches, and thinner, yellowishgreen foliage. Sylviculturally they have rather different effects.

Various provenance trials of Pinus contorta have been planted in different parts of Great Britain, and preliminary assessments of the different plots show that coastal lots from Oregon and Washington grow fastest, while there is a suggestion that, if the whole range of the tree along the Pacific coast is considered, plants from the northern part of this range grow more slowly in Britain than plants from farther south. 
With the inland forms, the opposite may prove to be the case. The longest branches appear to grow on trees from the most northerly Pacific coastal origins, while the shortest branches tend to grow on trees from inland regions in the south. Generally there are more branches per whorl on the coastal forms. The coastal trees have shorter needles, averaging $I^{3}$ in., while inland forms have needles averaging $2-2 \frac{1}{2}$ in. in length; the inland lodgepole pine does not hold its needles as long as the coastal form, on which needles are retained for three years or more. All the trees of coastal origin have completely, or almost completely, killed out the ground vegetation; but very little suppression has been effected by inland forms.

These papers were preceded by an account by James Macdonald (director of research and education, Forestry Commission) of recent developments in forestry nursery technique. The success of a large planting programme depends on a continuous supply of suitable planting stock, and thus the raising of plants in the nursery has always been regarded as of prime importance. Various difficulties have been encountered in running nurseries at high pressure for the provision of young trees, almost entirely coniferous ; during the nineteen-thirties, for example, there was a serious diminution in the fertility of many nurseries. One spproach to the solution of this problem was made by the late Dr. M. C. Rayner, who established at Wareham, in Dorset, a nursery which made an important break with established practice. Instead of using an agricultural soil, Dr. Rayner set to work on a piece of uncultivated heathland and, by shallow cultivation, subsoiling, and a liberal use of composts, produced successive crops of seedlings much larger than had ever been raised before. Her technique, with various modifications, was widely used elsewhere, and a considerable proportion of the seedlings produced to-day are grown in 'heathland' nurseries. These nurseries, when properly sited and managed, are remarkably free from weeds, and the saving in weeding costs is an important item to be set off against the expense of the other operations. This technique did not solve the problems of the ordinary forest nursery; it avoided them. They were approached, however, from another side; by means of partial soil sterilization, with steam, with formalin and with other chemicals, combined with appropriate fertilizer treatment, nursery soils which had been producing very poor seedlings began to yield plants as good as those in heathland nurseries, while there was also a substantial reduction in weeding. The complex of factors involved in this and in other nursery processes is being studied by a committee which was set up by the Forestry Commission in 1944, under the chairmanship of the late Prof. F. T. Brooks, and on which Drs. E. M. Crowther and A. B. Stewart are active members. It has been found possible to raise with fertilizers seedlings as good as those produced with the aid of compost or sterilization ; it has also been established that many conifers, and particularly Sitka spruce, are highly sensitive to lime in the nursery and that some of the trouble in the established nurseries was due to injudicious liming. Because it is possible to raise seedlings which can be handled at the end of their first year, it has been possible to use many more two-year-old transplants in moorland afforestation. These are less costly than the three/four-year old plants formerly used.

The prospect of effective weed-control in seed-beds has been brightened by the use of mineral oils applied before the tree seedlings emerge, while other directions in which research is proceeding are in the use of overhead irrigation and in the attempt to raise two or three successive crops of seedlings in a season with the help of bottom heat.

\section{NEWS and VIEWS}

\section{Physiology in the University of London: Prof. Geoffrey Harris}

Prof. Geoffrey Harris, who has been appointed to the Fitzmary chair of physiology in the University of London, is known for his work on the control of the pituitary gland. This chair, of which he is the first holder, is named after Simon Fitzmary (1492), the founder of Bethlem Royal Hospital; it is attached to the Department of Neuro-Endocrinology of the Maudsley Hospital. Prof. Harris was first trained in anatomy and medicine in Cambridge, and, after qualifying at St. Mary's Hospital, London, became in 1940 demonstrator and later lecturer in anatomy at Cambridge; in 1948 he was appointed lecturer in the Department of Physiology. His research work has been on the anatomy and physiology of the pituitary gland and on the control of pituitary secretions by the nervous system. In his recent work he has modified the technique of implanted electrodes and placed small secondary coils under the scalp with an electrode placed in various sites near the supra optic nuclei. By using a primary coil surrounding the animal, he was able to produce endocrine effects on urine flow, cestrus, etc., without otherwise disturbing the animal. He has shown the existence of a hormonal link, carried by a system of portal vessels, between the nervous and secretory structures. The pituitary forms the main link by which external events affect the endocrine glands via the nervous system, and this clarification of how this is effected helps in our understanding of both. His work is characterized by great skill in difficult operative techniques and in masterly grip of the physiological and anatomical problems of his chosen field. Prof. Harris's many friends will be glad that in his new post he will be able to devote himself almost entirely to research in this rapidly developing field, in which he has done so much to clarify our ideas during the past fifteen years.

\section{H. G. Smith (1852-1924) : a Pioneer Australian Chemist}

AN interesting centenary has recently been observed in Sydney, marking the birth on July 26, 1852, of Henry George Smith, a pioneer worker on the chemistry of the Australian flora. Smith was born at Littlebourne, in Kent, and emigrated to Australia in 1883. He amplified his scanty scientific training while holding a humble post at the Sydney Technological Museum, and in 1891 published his first original paper, announcing the discovery of barytes in the Hawkesbury sandstones at Sydney. In 1895 he became mineralogist at the Museum. An ensuing paper on eucalyptus kinos and the occurrence of 